\title{
PRODUÇÃO, CARACTERIZAÇÃO E QUALIDADE FISIOLÓGICA DE SEMENTES DE QUATRO ACESSOS DE Stylosanthes
}

\author{
Larissa de Souza Pereira ${ }^{1}$; Claudinéia Regina Pelacani ${ }^{2}$; Lourival Palmeira Gonçalves \\ Neto $^{3 ;}$ Gabriel Santos de Jesus ${ }^{4}$. \\ 1. Bolsista PIBIC/CNPq, Graduanda em Agronomia, Universidade Estadual de Feira de Santana, e-mail: \\ lary_xique@hotmail.com \\ 2. Orientadora, Departamento de Ciências Biológicas, Universidade Estadual de Feira de Santana, e-mail: \\ claudineiapelacani@gmail.com \\ 3. Mestrando em Recursos Genéticos Vegetais, Departamento de Ciências Biológicas, Universidade Estadual de Feira de \\ Santana, e-mail: lourivalpgneto@yahoo.com.br \\ 4. Graduando em Agronomia, Departamento de Ciências Biológicas, Universidade Estadual de Feira de Santana, e-mail: \\ santosgabrie196@hotmail.com
}

PALAVRAS-CHAVE: Estilosantes, sementes, produção.

\section{INTRODUÇÃO}

O gênero Stylosanthes possui 50 espécies distribuídas em todo o mundo, sendo o Brasil um dos países mais importante para o gênero, com 31 das espécies descritas. Destacam-se pelo seu potencial forrageiro, pois apresenta alta produção de biomassa com elevado nível de proteína e excelente qualidade de forragem, além de ser tolerante ao déficit hídrico (Costa, 2006). As espécies desse gênero são propagadas preferencialmente por sementes e o seu plantio é realizado comumente em consórcio com gramíneas. Porém, a grande maioria dos Stylosanthes produz uma pequena quantidade de sementes (Costa, 2006), o que eleva o custo de produção, se fazendo necessário estabelecer protocolos de produção de sementes desse gênero com o intuito de auxiliar os produtores com essa demanda.

Para o uso adequado das sementes é necessário conhecer as suas características físicas e sua qualidade fisiológica. Essas características são importantes, pois garantem um material de maior uniformidade de peso, tamanho, fidelidade genética e das propriedades fisiológica quanto à germinação, emergência de plântulas e obtenção de mudas vigorosas, e seu conhecimento se tornam ainda mais importante quando as espécies são oriundas de cultivos tradicionais ou de origem espontânea (MATHEUS E LOPES, 2009).

\section{MATERIAL E MÉTODOS}

Os experimentos foram realizados na Unidade Experimental Horto Florestal da Universidade Estadual de Feira de Santana e todos os procedimentos de beneficiamento, caracterização de sementes e teste de viabilidade laboratorial foram realizados no Laboratório de Germinação (LAGER).

\section{Produção de sementes}

O experimento foi conduzido em viveiro, em delineamento experimental em blocos casualizados, com três repetições. As mudas foram produzidas a partir de sementes de quatro acessos que fazem parte da coleção de germoplasma da UEFS. As sementes passaram por prétratamento germinativo para superação de dormência com o auxilio de lixa e foram semeadas direto em vasos de $5 \mathrm{~L}$ a uma profundidade de $3 \mathrm{~cm}$. A colheita das sementes foi realizada em dois períodos após inicio da floração, em março e maio de 2019.

Os tratamentos foram os quatro acessos de Stylosanthes, sendo considerada cada 
planta uma unidade experimental. Todas as plantas no bloco foram avaliadas. As sementes utilizadas nos próximos experimentos foram provenientes do banco, pois a produção de sementes do experimento de multiplicação foi relativamente baixa, coletando dois acessos dos quatro semeados. As sementes coletadas dos dois acessos foram beneficiadas, caracterizadas e armazenadas em sacos tipo pipoca e colocadas em vasos de vidro contendo sílica gel, segundo (AMÉRICO, 2015).

\section{Caracterização de sementes}

Para realizar biometria das sementes dos quatro acessos, foram utilizadas sementes dos acessos codificados provenientes do banco de germoplasma de forrageira da UEFS, pois na colheita na produção de semente, se obteve apenas sementes de dois acessos. Uma subamostra retirada de cada acesso, composta de 200 sementes foi dividida em quatro repetições e analisadas quanto às medidas de comprimento (distância do ápice à base), largura e espessura (região mediana) utilizando paquímetro digital $(\mathrm{mm})$. Uma segunda subamostra, composta de 200 sementes e dividida em quatro repetições, foram utilizadas para obtenção da massa fresca (g). O conteúdo de umidade das sementes foi avaliado mediante a secagem pelo método padrão (RAS), em estufa de circulação forçada de ar, $105^{\circ} \mathrm{C}$ por 24 horas. O conteúdo de umidade será analisado pela expressão: $\mathrm{CU}=($ Peso inicial - Peso final $) /($ Peso inicial $) \mathrm{x}$ $100 \%$.

Ao final das medições foram separados lotes de 100 e 1000 sementes para cada acesso e obtidas às massas (g) com auxílio de balança analítica. Utilizando uma mini-cartela de cores RHS (Royal Horticultural Society), foi comparada a variação da coloração da testa das sementes para os quatro acessos de Stylosanthes.

\section{Análise de germinação e desenvolvimento pós-seminal}

Visando estabelecer as condições ideais para o desenvolvimento e o tempo para formação de plântulas, as sementes foram submetidas às seguintes condições: Dispostas uniformemente em placa de petri sobre substrato composto de duas folhas de papel de germinação estéril, embebidas com água destilada de acordo com as Regras para Análise de Sementes (Brasil, 2009). Estas permaneceram em câmara de germinação tipo BOD, com temperatura de $20 / 30^{\circ} \mathrm{C}$ e fotoperíodo de 12 horas por um período de 14 dias. A partir das observações foi possível determinar: taxa de germinação (\%), tempo médio de geminação (dias) e índice de velocidade de germinação (sem. dia $^{-1}$ ). Após finalização do período experimental foram realizadas análises físicas das plântulas com medição do comprimento da comprimento da raiz, comprimento total das plântulas normais, que apresentavam a total expansão dos cotilédones.

O delineamento foi inteiramente casualizado com quatro repetições, e os dados foram submetidos a analise de variância (ANOVA) e as médias comparadas pelo teste de Tukey a $5 \%$ de probabilidade. . As plântulas foram utilizadas para produção de mudas e obtenção de sementes para renovação das sementes da Coleção de Germoplasma de Forrageiras da Universidade Estadual de Feira de Santana.

\section{RESULTADOS E/OU DISCUSSÃO}

\section{Produção e coleta de sementes}

Os acessos BGF 08-018 e BGF 08-034 apresentaram floração após 5 meses de implantação do experimento, demonstrando uma precocidade no lançamento da parte 
reprodutiva quando comparado com a BGF 08-016 e a Cultivar Campo Grande que floresceram após 08 meses do cultivo. Esse tipo de comportamento parece estar relacionado com a origem dos acessos BGF 08-018 e BGF 08-034, encontrados em regiões próximas de Feira de Santana, a exemplo do BGF 08-018 com origem em Candeal - BA e BGF 08-034 com origem em Feira de Santana-Ba, respectivamente. A espécie S. scabra Vogel, floresce e frutifica simultaneamente de outubro a agosto (Costa, 2006; Costa et al., 2008; Fortuna-Perez et al., 2011), correspondendo ao mesmo período de floração e frutificação observados nesse estudo.

Quanto à produção de sementes dos acessos BGF 08-018 e BGF 08-034, verificou-se que o numero de sementes/planta foi baixo. Os acessos BGF 08-034 e BGF 08-018 produziram em média 7 sementes/planta, não ultrapassando o total de 104 e 100 sementes, respectivamente. No período de avaliação os demais acessos não produziram sementes. Para as avaliações biométricas e fisiológicas utilizaram-se as sementes mantidas no próprio banco da UEFS (BGF 08-16 e a Cultivar Campo Grande). Vale ressaltar que para renovação de banco de sementes, a etapa de multiplicação é um processo importante para a manutenção das coleções, obtendo sementes novas e viáveis. Costa (2006) salienta que a grande maioria das espécies de estilosantes produzem pequenas quantidades de sementes, sendo um fator primordial para o sucesso da multiplicação.

\section{Caracterização de sementes}

Em relação à coloração do tegumento das sementes (Figura 1) observou-se os seguintes resultados: acessos BGF 08-018 e BGF 08-034 predominara as cores Brown (RHS 199A); acesso BGF 08-016 Orange Brown (RHS N170A) e a Cultivar predominou Dark Brown (RHS 200A). Segundo Haliski et al. (2013), estudos morfológicos de sementes podem auxiliar sobre a qualidade fisiológica, respostas de germinação, além de favorecer a conservação e utilização da espécie. Além da variabilidade da coloração do tegumento, as sementes de estilosantes variaram em relação às características biométricas (Tabela 1).

Figura 1. Coloração e formato das sementes dos acessos de Stylosanthes. (1) Candeal (Coloração Brown), (2) Queimadas (Coloração Orange Brown), (3) Feira de Santana (Coloração Brown), (4) Cultivar Campo Grande (Dark Brown).

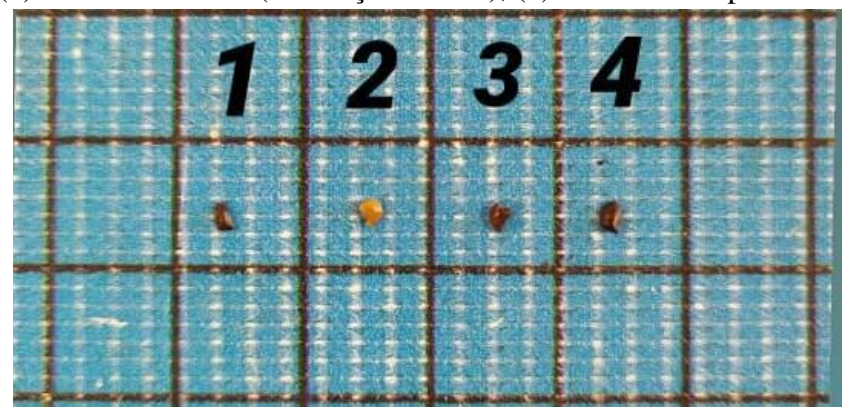

Tabela 1. Valores médios das características de sementes de Stylosanthes

\begin{tabular}{|c|c|c|c|c|}
\hline \multirow[t]{2}{*}{ Acesso } & $\mathrm{CS}$ & LS & P100S & P1000S \\
\hline & (mm) & $(\mathrm{mm})$ & (g) & (g) \\
\hline BGF 08.018 & $2,035 b^{*}$ & $1,45 b^{*+}$ & $0,162 \mathrm{~d}^{* *}$ & $1,650 \mathrm{~d}^{*+*}$ \\
\hline BGF 08.016 & $2,015 \mathrm{bc}$ * & $1,41 \mathrm{bc} *$ & $0,220 b^{* *}$ & $2,207 b^{\text {"* }}$ \\
\hline BGF 08.034 & $1,905 \mathrm{c} *$ & $1,36 \mathrm{c}^{*+}$ & $0,202 \mathrm{c}$ ** & $2,045 \mathrm{~cm}$ \\
\hline Cultivar & $2,372 \mathrm{a}=$ & $1,61 \mathrm{a} *$ & $0,280 \mathrm{a}=$ & $2,835 \mathrm{a}$ * \\
\hline $\mathrm{CV}(\%)$ & 9.63 & 8.67 & 1.72 & 0.31 \\
\hline
\end{tabular}

Médias seguidas por mesma letra nas colunas não diferem entre si, pelo teste de Tukey a $1 \%$ (**). Médias seguidas por 
mesma letra nas colunas não diferem entre si, pelo teste de Tukey a 5\% (*). CS= Comprimento da semente; LS= Largura da semente; Peso de 100 sementes; Peso de 1000 sementes.

As sementes apresentaram comprimento variando entre 1,90 a 2,37 $\mathrm{mm}$, a largura variando de 1,36 a 1,61 mm, tendo a Cultivar como melhor acesso para as duas variáveis analisadas. A espessura e o conteúdo de umidade não apresentaram significância nas médias (dados não apresentados). Em relação ao peso de 100 e 1000 sementes, o acesso que apresentou menor peso foi o BGF 08-018. As sementes que apresentaram as maiores dimensões $(\mathrm{C} \times \mathrm{L})$ foram as que apresentaram maior peso, podendo refletir na diversidade do processo de germinação e obtenção de mudas mais vigorosas. Sementes da Cultivar Campo grande apresentaram as maiores dimensões (Tabela 1).

\section{Análise de germinação e desenvolvimento pós-seminal}

Observa-se na Tabela 2 que o acesso BG 08-016 foi o que obteve maior quantidade de sementes germinadas, o acesso BGF 08-018 foi o segundo que mais germinou, mas não diferiu da Cultivar. Sementes do acesso BGF 08-034 foi o que apresentou a menor porcentagem de germinação. Em relação ao tempo médio de germinação, as sementes mostraram médias variando entre 1,5 a 3,2 dias para emitirem a radícula. O acesso BGF 08016 foi o que levou menos dias para que as sementes germinassem, diferindo dos demais acessos avaliados. Esse mesmo acesso foi o que apresentou a maior velocidade de germinação (Tabela 2). A velocidade de germinação observada foi quase 2 vezes maior quando comparada aos demais acessos. Foi possível observar também variação quanto à viabilidade das sementes. Pelo teste de germinação as sementes do acesso BGF 08-16 foram as que apresentaram a maior porcentagem de sementes germinadas. Por se tratar de um material selecionado, esperava-se que a sementes da Cultivar Campo Grande mostrassem uma germinação elevada e rápida. Através desse estudo foi observado que existem acessos de estilosantes com características importantes e que testes de germinação podem ser utilizados como critério para detectar a variabilidade entre eles.

Tabela 2. Valores médios e percentuais de germinação de sementes de Stylosanthes.

\begin{tabular}{|c|c|c|c|}
\hline Acesso & $\begin{array}{l}\text { G } \\
\text { (\%) }\end{array}$ & $\begin{array}{l}\text { TMG } \\
\text { (dias) }\end{array}$ & v \\
\hline BGF 08.018 & $82,00 \mathrm{ab}^{\text {*t }}$ & $2,137 a b$ * & $0,467 a b^{* *}$ \\
\hline BGF 08.016 & $99,00 \mathrm{a}$ * & $1,492 a^{*}$ & $0,717 \mathrm{a}$ ** \\
\hline BGF 08.034 & $40,00 \mathrm{c}$ * & $3,202 b$ * & $0,322 b$ "* \\
\hline Cultivar & $60,00 \mathrm{bc} *$ & $2,320 a b$ \# & $0,435 b$ * \\
\hline $\mathrm{CV}(\%)$ & 15.89 & 21.80 & 25.66 \\
\hline
\end{tabular}

Médias seguidas por mesma letra nas colunas não diferem entre si, pelo teste de Tukey a 1\% (**). Médias seguidas por mesma letra nas colunas não diferem entre si, pelo teste de Tukey a 5\% (*). G= Germinação; TMG= Tempo médio de germinação; $\mathrm{V}=$ Velocidade.

\section{CONSIDERAÇÕES FINAIS}

A variabilidade genética encontrada nos acessos de Stylosanthes é muito importante para a seleção de genótipos promissores ao melhoramento genético da espécie. O acesso BGF 08-016 se equiparou a Cultivar Campo Grande, apresentando as melhores médias para a germinação e na qualidade fisiológica das sementes. Para o desenvolvimento pós-seminal, os outros dois acessos (BGF 08-018 e BGF 08-034) foram superiores a Cultivar. Para a etapa de multiplicação, a obtenção de sementes novas para a reposição do banco de sementes de 
forrageiras da UEFS foram parciais, sendo necessário ampliar o número de plantas amostradas em campo.

\section{REFERÊNCIAS}

AMÉRICO, F. K. A. Germinação e armazenamento de sementes de Stylosanthes SW. Em diversos ambientes. Dissertação (Mestrado) - Universidade Estadual de Feira de Santana, Programa de Pós- Graduação em Recursos Genéticos Vegetais, 2015.

COSTA, N. M. S. Revisão do gênero Stylosanthes Sw. 2006. 47f. Tese (Doutorado em Engenharia Agronômica) - Universidade Técnica de Lisboa, Lisboa. 2006.

FORTUNA-PEREZ, A. P.; SILVA, M. J.; TOZZI, A. M. G. A. Stylosanthes (LeguminosaePapilionoideae-Dalbergiae) no estado de São Paulo, Brasil. Rodriguésia, n.62, v.3, p.615628. 2011.

LOPES, J., Fortes, C.A., Souza, R.M. et al. Importância da qualidade da semente para o estabelecimento de pastagens. PUBVET, Londrina, v. 3, n. 13, 2009.

MARCOS FILHO, J. Fisiologia de sementes de plantas cultivadas. Londrina: ABRATES, 2015. 659 p. il, color.

Stylosanthes in Flora do Brasil 2020 em construção. Jardim Botânico do Rio de Janeiro. Disponível em: <http://reflora.jbrj.gov.br/reflora/floradobrasil/FB29854>. Acesso em: 20 Jul. 2019. 